\title{
SCOT Answers, Other Questions. A Reply to Nick Clayton
}

Citation for published version (APA):

Bijker, W. E., \& Pinch, T. (2002). SCOT Answers, Other Questions. A Reply to Nick Clayton. Technology and Culture, 43, 361-369. https://doi.org/10.1353/tech.2002.0050

Document status and date:

Published: 01/01/2002

DOI:

10.1353/tech.2002.0050

Document Version:

Publisher's PDF, also known as Version of record

\section{Please check the document version of this publication:}

- A submitted manuscript is the version of the article upon submission and before peer-review. There can be important differences between the submitted version and the official published version of record.

People interested in the research are advised to contact the author for the final version of the publication, or visit the DOI to the publisher's website.

- The final author version and the galley proof are versions of the publication after peer review.

- The final published version features the final layout of the paper including the volume, issue and page numbers.

Link to publication

\footnotetext{
General rights rights.

- You may freely distribute the URL identifying the publication in the public portal. please follow below link for the End User Agreement:

www.umlib.nl/taverne-license

Take down policy

If you believe that this document breaches copyright please contact us at:

repository@maastrichtuniversity.nl

providing details and we will investigate your claim.
}

Copyright and moral rights for the publications made accessible in the public portal are retained by the authors and/or other copyright owners and it is a condition of accessing publications that users recognise and abide by the legal requirements associated with these

- Users may download and print one copy of any publication from the public portal for the purpose of private study or research.

- You may not further distribute the material or use it for any profit-making activity or commercial gain

If the publication is distributed under the terms of Article $25 \mathrm{fa}$ of the Dutch Copyright Act, indicated by the "Taverne" license above, 
EXCHANGE

SCOT Answers, Other Questions

A Reply to Nick Clayton

WIEBE E. BIJKER and TREVOR J. PINCH

We welcome the opportunity offered by the editor of $T \ll C$ to engage in this debate. As well as addressing specific questions raised by Nick Clayton we hope to move the discussion forward by focusing in particular upon the role of theoretical concepts in the history of technology. Clayton criticizes our account of the history of the bicycle and concludes that overall SCOT does not answer. We will readily concede that Clayton, as a specialist historian of the bicycle, is able to offer a more complete historical narrative drawing upon research not available to us eighteen years ago, but we will also argue that his conclusion about the (in)adequacy of SCOT does not hold and is based upon a misconception of the relationship between theory and empirical evidence in the history of technology (or indeed any other field).

Our essay "The Social Construction of Facts and Artifacts: Or How the Sociology of Science and the Sociology of Technology Might Benefit Each Other," in which we outlined the approach known as SCOT, was progranmatic. ${ }^{1}$ The original journal article (longer, and published three years earlier than the account in the book) was published as a discussion paper. ${ }^{2}$ It reviewed different bodies of literature and was written to stimulate theoretical debate over how best to do the sociology and history of technology. It used historical vignettes (in the original version drawn from both science

Dr. Bijker is a member of the Faculty of Arts and Culture at the Universiteit Maastricht; his essay on Dutch water technology is forthcoming in the July 2002 issue of Technology and Culture. Dr. Pinch teaches in the Department of Science and Technology Studies at Cornell University in Ithaca, N.Y.

(C2002 by the Society for the History of Technology. All rights reserved. 0040-165X/02/4302-0006\$8.00

1. Trevor J. Pinch and Wiebe E. Bijker, "The Social Construction of Facts and Artifacts: Or How the Sociology of Science and the Sociology of Technology Might Benefit Each Other" (hereinafter SCOFA), in The Social Construction of Technological Systems, ed. Wiebe E. Bijker, Trevor Pinch, and Thomas P. Hughes (Cambridge, Mass., 1987), 17-50.

2. Social Studies of Science 14 (1984): 339-441 


\section{TECHNOLOGY AND CULTURE}

and technology) to illustrate the sort of theoretical approach we advocated. The book published by one of us, although going into more empirical detail, was explicitly conceived of as a theoretical contribution toward understanding the development of technology and offered an explicit disclaimer not to offer new findings on the history of the bicycle. ${ }^{3}$ Given this, we could easily dismiss Clayton's critique as misdirected and irrelevant. We will not do so, however. We want to take up the challenge for two very different reasons. The first is that indeed we highly value empirical research as one of the cornerstones of technology studies. This implies that even when we use case studies merely as illustrative examples we would like them to be empirically sound. A discussion about their empirical adequacy is thus wholly appropriate. The second reason to take up Clayton's challenge is a more fundamental issue: Clayton seems to misunderstand the interplay of theoretical and empirical work in the history (and sociology) of technology.

We will thus take this debate into two arenas: first, the empirical details of the history of the bicycle; second, the interaction between theoretical concepts and empirical data. (In practice it will be difficult to separate the two.) We note in passing that Clayton has himself made some factual errors. However, we first need to clear away some mistakes. Clayton misunderstands what constitutes SCOT. He shows this confusion early on when he writes that "All of the contributors to The Social Construction of Technological Systems claimed to be following the SCOT approach." This is patently false. In the general introduction to that volume the editors explained that "three approaches played a more or less dominant role and hence have guided the studies in this volume" (p. 4), and named these as "the social constructivist approach," the "systems" approach, and the "actor networks" approach. ${ }^{4}$ In defense of Clayton, we note that many other careless readers have made this mistake. We will not use our limited space here to summarize SCOT. ${ }^{5}$ In the context of this debate, it is sufficient to follow Clayton's discussion of three SCOT concepts.

Clayton discusses three (or rather four) central concepts of SCOT: relevant social groups, interpretative flexibility, and closure and stabilization. His general strategy is to point to (supposed) empirical errors in the bicycle

3. Wiebe E. Bijker, Of Bicycles, Bakelites, and Bulbs: Toward a Theory of Sociotechnical Change (Cambridge, Mass., 1995) (hereinafter 3B).

4. These approaches are presented in the chapters by, respectively, Pinch and Bijker, Hughes, and Michel Callon.

5. For a careful definition of what constitutes SCOT, in comparison to other approaches and with attention to how the concepts evolved over more than sixteen years, see W. E. Bijker, "Social Construction of Technology," in International Encyclopedia of the Social and Behavioral Sciences, ed. Neil J. Smelser and Paul B. Baltes (Oxford, Amsterdam, 2001), 15522-27; Trevor Pinch, "The Social Construction of Technology: A Review," in Technological Change: Methods and Themes in the History of Technology, ed. Robert Fox (Amsterdam, 1996), 17-35; W. E. Bijker, "Sociohistorical Technology Studies," in Handbook of Science and Technology Studies, ed. Sheila Jasanoff, et al. (London, 1994), 229-56. 
case study and then conclude that the concepts must be wrong. This is an elementary non sequitur. ${ }^{6}$ Theoretical concepts are not directly based upon empirical facts. Theoretical concepts are "invented" by researchers to help them to make sense of empirical data. As we will concede below, Clayton may be right to correct Bijker's historical work in one instance, but the conclusion he draws from this about the value of SCOT is a logical error.

We now first turn to Clayton's discussion of the concept of relevant social group. He makes two mistakes. The first is simply misreading our text, and the second is an example of his misunderstanding of the place of theoretical work. Nowhere did we claim that women actually rode the highwheeled ordinary. On the contrary, we highlighted the problems that existed for women (SCOFA, p. 34; 3B, pp. 42-43). But since some readers might have argued that it was irrelevant to mention the problems that women might have had with respect to bicycles, we mentioned the efforts of respected engineers such as Starley and Hillman to develop a highwheeled women's bicycle. As Bijker concluded, "this ... did not become a success, and few sidesaddle bicycles were sold" (3B, 43). So Clayton's criticism of our interpretation the picture of James Starley's niece on an ordinary is simply wrong. ${ }^{7}$ His misreading is not surprising, however, when it is realized how completely he misses the point of the concept of the relevant social group. His interpretation of this concept is that of "user groups." The whole point of introducing the concept of relevant social groups was to get away from such narrow definitions of who and what are relevant in the development of technology. The concept of relevant social group was introduced "to avoid the pitfall of retrospective distortion" $(3 \mathrm{~B}, 45)$. Our suggestion is that women played a role in the development of the bicycle exactly because they did not use the high ordinary, but wanted to bicycle. Relevant social groups need to be defined more broadly than the standard user groups when one wants to avoid Whiggish history of technology.

Another complaint leveled by Clayton is that we "recruited half the population of England into a relevant social group" thereby showing the lack of subtlety in the social group idea. Clayton quotes Suzanne Moon in his support, using her point that analysts unavoidably play a role in delineating social groups. First, it is indeed, as Moon observes, a decision by the analyst. But this is only so in the trivial sense that all research (whether historical, sociological, or natural-scientific) must involve analysts who may do a better or worse job of it depending upon their analytical and interpretative skills. The conclusion from Moon's observation thus can only be that indeed SCOT is about doing interpretative research, not that it is flawed

6. Although we will not elaborate this point, it shows Clayton's naivve empiricist attitude, reminding us of the philosophers of the Wiener Kreis, who hoped to show that theoretical statements followed directly from empirical statements.

7. Even Clayton's reference to Woodforde as the source is wrong: Bijker studied the Ladies' Ariel, in material and paper form, in the Science Museum in London $(3 B, 44)$. 


\section{TECHNOLOGYAND CULTURE}

because it depends upon the view of the analyst. However, the analyst is of course not completely on her or his own. The whole point of theoretical concepts is to enable and constrain the analysts in their interpretive work. In this case of relevant social groups, Bijker has proposed that they are not only relevant for the analyst (and her or his interpretation of the technol-

APRIL ogy), but also for the actors. ${ }^{8}$ The actors themselves give clues as to which groups are relevant. This process of "following the actor" suggested, for example, splitting the nonbicycling population (certainly much more than half of Britain) into anticyclists, elderly men, and women. It might have been useful (but we deemed not so) to further split the relevant social group of women into different classes or into different geographical subgroups. Again: the researcher (in this case us) can be criticized for making the wrong decision, and a debate will develop over whether another set of relevant social groups would do a better explanatory job. But to criticize a framework for relying upon analysts' interpretive work is to misunderstand the character of doing historical research.

Clayton's second critique is directed toward the concept of interpretative flexibility. Clayton argues that Bijker has relied too much on Woodforde in arguing for Dunlop's view of the pneumatic tire as an antivibration device. Clayton claims that "it is well-documented" that Dunlop was aware of its lower rolling resistance and thus of the pneumatic tire as a speedincreasing device. We hardly dare to challenge this argument of authority, since we are not bicycle historians. However, again, in no way does this weaken the concept of interpretative flexibility, for all the same reasons that we cited previously in relation to the concept of relevant social groups. ${ }^{9}$

But there is more to say about this historical episode. Of course, Clayton is right that we based our original account mainly on Woodforde, who evidently is not a respected member of the club of bicycle historians. ${ }^{10}$ But in preparing this response we took a dip into Bijker's boxes of photocopies and found some of the key patents, which seem to suggest some critical questions about Clayton's "well-documented" account. Dunlop's first patent does indeed mention two purposes of his invention, in the following order: "immunity from vibration" and "ensuring increased speed." "This is a very brief patent of half a page, without any drawings or technical details. His second patent, of 1889 , is more detailed and does contain a technical drawing of the patented tire. In this patent he claims that "a hollow air inflated

8. See section 2.4 in $3 B$.

9. Of course, for a reflexive adherent of interpretative flexibility, such as Malcolm Ashmore or Steve Woolgar, Clayton's argument only strengthens the case for interpretative flexibility because it shows there is interpretative flexibility over this putative case of interpretative flexibility!

10. John Woodforde, The Story of the Bicycle (New York, 1970).

11. J. B. Dunlop, "An Improvement in Tyres of Wheels for Bicycles, Tricycles, or other Road Cars," U.K. patent 10,607, 23 July 1888. 
India-rubber tyre ... possesses several important advantages over the solid india-rubber tyres at present in use, inasmuch as . . . it is more elastic, all vibration and shock when riding or driving over rough roads being intercepted ..., consequently little or no jar is experienced by the rider or riders. ..."12 However, there is no mention of the tire's purpose of enhancing the speed. Clayton perhaps still wants to argue that Dunlop's History of the Pneumatic Tyre offers more solid evidence than his own detailed patent of 1889. May we, however, cast a little more doubt on the claim that enhancing the speed was all that the pneumatic tire was about? Two other patents seem to stress the antivibration purpose as well. W. E. Bartlett in an 1890 patent only mentions that his tire construction is "free to cushion the wheel more effectively than a solid rubber tyre." 13 And in the famous patent by C. K. Welch, the inventor states: "The chief objects of my invention are easy running, reduction of vibration and security of the rubbers to the metal rims or felloes." ${ }^{4}$ In the subsequent paragraph elaborating upon the purpose of the new invention only the anti-vibration goal is mentioned, and "easy running" (not to mention enhancing speed) is not referred to at all. Since these patents are from 1890 , it is not unreasonable to assume that a general recognition that air tires were for going faster, rather than for going more smoothly, took a little longer than Clayton claims.

Additionally, we can note here a further mistake that Clayton makes about the relations between empirical evidence and theoretical work. $\mathrm{He}$ asks, quoting Aristotle Tympas, "Is the history of an isolated artefact the proper unit of theoretical abstraction?" Well, sometimes it may be. But the concept of interpretative flexibility certainly was not based on the analysis of one artifact. First, as Clayton notes himself, the concept was initially developed in quite another domain - the sociology of scientific knowledge. And, second, Bijker did study six different cases in the history of technology before deciding that interpretative flexibility was indeed a useful concept. ${ }^{15}$ The point we want to make here is that Clayton confuses the invention and development of a theoretical concept with its presentation and explanation. We chose to explain certain aspects of the SCOT approach by using the bicycle as an illustration (as Bijker later used Bakelite and the fluorescent lamp to explain other aspects), but the theoretical approach itself does not rest upon this one example.

12. J. B. Dunlop, "Improvements in Wheel Tyres for Cycles and other Vehicles, and in Means for Securing the same to the Wheel Rims," U.K. patent 4116, 8 March 1889.

13. W. E. Bartlett, "Improvements in the Elastic Tyres or Rims of the Wheels of Velocipedes and other Vehicles," U.K. patent 16,348, 14 October 1890.

14. C. K. Welch, "Improvements in Rubber Tyres and Metal Rims or Felloes of Wheels for Cycles and other Light Vehicles," U.K. patent 14,563, 16 September 1890.

15. These cases were: the bicycle, Bakelite, the fluorescent lamp, aluminum, the Sulzer weaving machine, the transistor. "Research on these cases was completed and did contribute to the shaping of the theoretical framework presented here. Space limitations, however, prevented their inclusion." (3B, 292 n. 12). 


\section{TECHNOLOG Y A N D CULTURE}

The discussion by Clayton of the concepts closure and stabilization is the weakest part of his argument. Or maybe we should say that his reading of our original texts is weakest here. He comments in a tone that suggests that he is correcting us: "They picked 1879 as the beginning date because it was the year of Lawson's Bicyclette, a prototype safety that failed to sell and passed largely unnoticed at the time. It was disinterred later by bicycle his-

APRIL

2002

VOL. 43 torians because it had similar features to the eventually successful Rover safety, and it continues to attract some interest because one survives in the London Science Museum." But this is exactly what we claimed when criticizing the linear model: "Some of the 'safety ordinaries' were produced commercially, whilst Lawson's Bicyclette, which seems to play an important role in the linear model, proved to be a commercial failure" (SCOFA, 29). Bijker further substantiates this by describing the critical reception of the Bicyclette: "Both the public and the trade just could not swallow the grotesque form of the Bicyclette, which was compared to a crocodile because of its elongated frame" $(3 \mathrm{~B}, 68)$.

Then Clayton seems to think that his disclosure of the fact that we identify the stabilization of the safety bicycle in one place as an eighteen-year period and in another as a nineteen-year period implies a critique of the concept of stabilization. It is exactly the opposite: our central argument has been that it is an unfruitful and inadequate account of the process of technological invention to focus attention on specific dates, and that instead the concept of stabilization occurring over a period of time is more helpful in interpreting technological invention. Accepting this theoretical view makes quibbling about eighteen or nineteen years rather silly. Clayton's focus on the exact dates of the beginning and the ending of this stabilization period, rather than on the pracess during the period, is not exceptional of course. It is a cornerstone in the standard empiricist view of the history of technology, but it was this cornerstone which we sought to replace by drawing attention to processes over time. ${ }^{16}$

Clayton's final pages are helpful to diagnose his perspective on the history of technology. Clayton concludes that "like the relevant social group or the technological frame, concepts of closure and stabilization must remain so flexible that they depend entirely upon the analyst's point of view." The difference between Clayton and us is not that we deny this; the difference is

16. Another illuminating specimen of this approach in the history of technology is offered by Angus Buchanan, although he casts the difference in terms of "individualsocial" rather than in terms of "moment-period": "But in the last resort it is more important to stress the individual, unique, and contingent quality of personal creativity than the element of social conditioning." R. A. Buchanan, "Theory and Narrative in the History of 'Technology," Technology' and Culture 32 (1991):365-76. See also the responses by John Law, "Theory and Narrative in the History of Technology: Response," 377-84, and Philip Scranton, "Theory and Narrative in the History of Technology: Comment," 385-93. 
that we positively value this characteristic of theoretical concepts and argue that exactly because of this characteristic they provide the much needed antidote against naïve empiricist ideas about doing history of technology. Here an interesting difference of view between Clayton and us emerges. Clayton seems to think that because concepts depend on the analyst's point of view the analyst must inevitably impose present-day views in doing history. Our view is just the opposite: by denying the key role of the analyst in interpreting historical data, and by thus rendering the inevitable interpretative work invisible and immune to critique, the risk of Whiggish and teleological history is much greater than when the role of theoretical concepts is made explicit. The specific social constructivist concepts that we have proposed were indeed designed to help historians guard against a view that "the whole history of technological development had followed an orderly or rational path, as though today's world was the precise goal toward which all decisions, made since the beginning of history, were consciously directed." ${ }^{77}$ We have wanted to warn against a view of history that suggests that "in looking for the roots of technology we must first have hold of the stem." For this purpose however, a crucial element in SCOT is indeed the concept of "technological frame," which Clayton does not discuss, perhaps because Bijker presented and explained this by using the case of Bakelite (in both The Social Construction of Technological Systems and 3B) rather than the bicycle.

Let us now take stock of this debate, which was held in two arenas: the empirical study of bicycle history and the interplay of theoretical and empirical work in the history of technology. In the first arena, Clayton claims to have corrected our view of the development of the pneumatic tire; we were prepared to accept such corrections, but then found some evidence in the patents that seems to cast doubt on Clayton's interpretation of the autobiographical story by Dunlop. On all the other points of substance we were disappointed to find that Clayton had either misread our text or perversely had taken the very points we made about bicycle history as a critique of our history.

In the second arena Clayton has allowed us to explicate several points. $\mathrm{He}$ is right when he observes that "SCOT is still alive and well," but he misses the reasons why. Researchers evaluate a theoretical approach by its usefulness in interpreting data. Here the score is positive for SCOT, since researchers decided to use (or be inspired by) it in a wide variety of studies. ${ }^{18}$

17. Eugene S. Ferguson, "Toward a Discipline of the History of Technology," Technology and Culture 15 (1974): 13-30, quoted in 3B, 7.

18. These include, for example: S. Beder, "Controversy and Closure: Sydney's Beaches in Crisis," Social Studies of Science 21 (1991): 223-56; Thomas J. Misa, "Controversy and Closure in Technological Change: Constructing 'Steel,"' in Shaping Technology/Building Society: Studies in Sociotechnical Change, ed. Wiebe E. Bijker and John Law (Cambridge, Mass., 1992), 109-39; K. Dibbets, Sprekende films: De komst van de- 


\section{TECHNOLOGY AND CULTURE}

It is worth elaborating this point. Researchers adopt concepts in so far as they are useful in understanding and explaining empirical cases. The test for a conceptual framework such as SCOT is thus whether it helps the researcher to make sense of case studies. It should be discarded when it loses its usefulness in that sense, and when another theoretical framework becomes available to do a better job. SCOT is not a recipe or "a simplistic

APRIL.

2002

VOL. 43 rule book." A theoretical approach can never be a foolproof data-mining machine: it will never make the researcher's craft superfluous, nor guard the researcher against errors of using the wrong sources, or of not finding the right sources. The implication is that theoretical frameworks typically are not used without modification and adaptation by the researcher (perhaps with the exception of brief essays and exercises in undergraduate teaching). We are indeed happy to report that the scholars whom we know who have tried to apply SCOT have adapted the concepts to fit their specific needs, and most of them finish their study by criticizing some aspect of the original SCOT model. ${ }^{19}$ This is precisely how good interpretative history should proceed. And this is what we would like to teach students. Clayton accuses us of corrupting students' knowledge by presenting an incorrect picture of bicycle history. We suggest, in contrast, that teachers continue to use our texts to teach students about doing interpretative history, and that they add Clayton's critique and this response to warn students of the corruptive power of naïve empiricism. ${ }^{20}$

Clayton begins his critique with three questions about SCOT: does it sell, does it work, and does in answer? We will take each in turn. Yes, SCOT sells. But not in the way Clayton thinks it does: the SCOT that sells (in the sense of being used by students of technology) is not the same that was presented almost twenty years ago. It is modified and adapted by many who use it (including ourselves), and it would indeed be preposterous for us to

geluidsfilm in Nederland, 1928-1933 (Amsterdam, 1993); Gregory C. Kunkle, "Technology in the Seamless Web: 'Success' and 'Failure' in the History of the Electron Microscope," Technology and Culture 36 (1995): 80-103; Diane Vaughan, The Challenger Launch Decision: Risky Technology, Culture, and Deviance at NASA (Chicago, 1996); Robert G. Arns, "The High-Vacuum X-Ray Tube: Technological Change in Social Context," Technology and Culture (1997): 852-90; H. v. d. Blonk, Changing the Order, Ordering the Change: Evolution of an Information System at Dutch Railways (Amsterdam, 2002).

19. We could give a long list of references, but perhaps most convincing are two studies, one that involves one of us criticizing and adapting the concept of relevant social groups; the other because it addresses bicycle history. Sce Ronald Kline and Trevor Pinch, "Users as Agents of Technological Change: The Social Construction of the Automobile in the Rural United States," Technology and Culture 37 (1996): 763-95; Paul Rosen, Framing Production: Technology, Culture, and Change in the British Bicycle Industry (Cambridge, Mass., 2002).

20. We certainly would add to this "teaching dossier" the insightful exchanges between Angus Buchanan, John Law, and Philip Scranton (n. 16 above), and between Ed Constant, Phil Scranton, and John Law and Vicky Singleton, Technology and Culture 41 (2000): 752-82. 


\section{BIJKER and PINCH. I SCOT Answers, Other Questions}

claim to "own" it. And yes, SCOT works. This is, however, less obvious and needs to be tried and demonstrated explicitly in each and every case. We, and many others, continue to find SCOT useful, but certainly do not consider it a panacea for every case-study. Finally, yes, SCOT answers, but not to the questions asked by Nick Clayton. It answers to issues of original, interpretative research-how to interpret empirical data without falling into traps of naïve empiricism and Whig history.

\section{Rejoinder by Nick Clayton}

I do not have space to defend myself against the charge of being a naïve empiricist so I will restrict my comments to Wiebe Bijker and Trevor Pinch's additional material. To begin, they say that nowhere did they claim that women actually rode the high-wheeled ordinary. This is true. What they wrote was "a young lady ... wrote to a magazine in 1885 about having used a bicycle, which at that date must have been a high-wheeled ordinary." They also included the powerfully confusing illustration of Starley's Ladies Ariel-not one I would choose for a serious text on bicycle history.

I challenged their assertion that J. B. Dunlop, in 1888, conceived his pneumatic tire simply as an antivibration device. ${ }^{2}$ I certainly did not claim that "enhancing the speed was all that the pneumatic tire was about." My view is unaffected by their quotations from later tire patents, of which there were thousands in the 1890s. The facts are that in 1888 Dunlop secretly timed the racer Walter Edlin on the first prototype over a measured mile on the Shore Road; that in 1889 he supplied the first production machine to William Hume, specifically for racing at Belfast Queen's College Sports; and that during that summer Dunlop was involved in many other track events, particularly at Portadown. ${ }^{3}$ This denies the suggestion that Dunlop was ambiguous about the air tire's speed potential. After the formation of the founder company in November 1889, Dunlop's personal views were subsumed in those of the controlling du Cros family, but they were cycle racers and convinced of the pneumatic tire's speed advantage. ${ }^{4}$ Paradoxically, it was problems with tires for the road rather than for track use, antivibration rather than speed, which took time to resolve.

1. Bijker, Of Bicycles, Bakelites, and Bulbs, 43. Bijker quotes Woodforde, who gave the 1885 date but no reference. Woodforde may have taken it from Rosemary Ratcliff, Dear Worried Brown Eyes (1970), a compilation of letters from women's magazines. Ratcliff quoted the Home Companion, 1885, but this title did not commence until 1897. It is therefore likely that the quote refers to the safety bicycle in 1897 , the second year of the Socicty Boom.

2. Bijker, Of Bicycles, Bakelites, and Bulbs, 84 .

3. J. B. Dunlop, The History of the Pneumatic Tyre (Dublin, [1925?]), 30. This was Dunlop's own history of his invention, published after his death by his daughter.

4. Dunlop's contemporary views on the tire question are detailed in an interview in the Wheelman, 21 October 1890. Arthur du Cros, Wheels of Fortune (London, 1938), 53. 
TECHNOLOGY AND CULTURE

However, the most controversial new hypothesis raised by Bijker and Pinch is that it was the pneumatic tire that killed off the ordinary, rather than the solid-tired safety. Faced with the challenge that this is a fundamental misconception, Bijker and Pinch remain silent.

Woodforde's book was not considered bad in 1970, but Bijker's book, twenty-five years on, repeated all the errors and then added some. It also

APRIL lacked Woodforde's style. Bijker and Pinch say that the test for SCOT is

2002 "whether it helps the researcher to make sense of case studies." Of Bicycles,

VOL. 43 Bakelites, and Bulbs makes much less sense than Woodforde, and it seems that it is the "interpretive flexibility" introduced by SCOT which is the reason why. ${ }^{5}$

5. This was the conclusion of the majority of the thirty or so bicycle historians at the Tenth International Cycling History Conference, Nijmegen, The Netherlands, 22-24 September 1999. 